\title{
BMJ Open Respiratory infections in preterm infants and subsequent asthma: a cohort study
}

\author{
Scott Montgomery, ${ }^{1,2,3}$ Shahram Bahmanyar, ${ }^{2,4}$ Ole Brus, ${ }^{1}$ Oula Hussein, ${ }^{1}$ \\ Paraskevi Kosma, ${ }^{5,6}$ Charlotte Palme-Kilander ${ }^{5}$
}

To cite: Montgomery S, Bahmanyar S, Brus 0, et al. Respiratory infections in preterm infants and subsequent asthma: a cohort study. BMJ Open 2013;3: e004034. doi:10.1136/ bmjopen-2013-004034

- Prepublication history for this paper is available online. To view these files please visit the journal online (http://dx.doi.org/10.1136/ bmjopen-2013-004034).

Received 15 September 2013 Accepted 23 September 2013

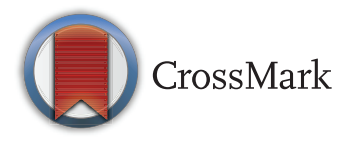

For numbered affiliations see end of article.

Correspondence to Professor Scott Montgomery, Clinical Epidemiology and Biostatistics, S-huset, Örebro University Hospital, Örebro 701 85, Sweden; Scott. montgomery@orebroll.se

\section{ABSTRACT}

Objectives: To investigate whether gestational age modifies the association of airway infections that result in hospital admission during the first year after birth, with subsequent asthma risk after age 5 years.

Setting: Hospital inpatients and a general population comparison group in Sweden followed for subsequent diagnoses in primary and secondary care.

Participants: National registers identified 42334 children admitted to hospital for respiratory infection in their first year after birth during 1981-1995, individually matched with 211594 children not admitted to hospital for infection during their first year.

Primary outcome: Asthma diagnoses and prescribed asthma treatments after the age of 5 years identified through registers.

Results: Cox regression was used to identify a HR (and $95 \% \mathrm{Cl}$ ) of 1.51 (1.47 to 1.51 ) for the association of respiratory infection before 1 year of age with asthma after age 5 years, after adjustment for sex, gestational age, chronic lung disease, maternal asthma and maternal smoking. When stratified by gestational age (and with additional adjustment for birth weight), there is statistically significant effect modification by gestational age, with the highest magnitude asthma risk among those born with a gestational age of less than 28 weeks, producing an adjusted HR of 2.22 (1.59 to 3.09 ). This higher magnitude asthma risk persisted until after age 10 years, but differences in risk by gestational age were less pronounced for asthma after age 16 years.

Conclusions: Extremely preterm infants are most likely to have chronic respiratory sequelae following respiratory infections in early life.

\section{INTRODUCTION}

Respiratory infection in the first year after birth, ${ }^{1-3}$ and preterm birth ${ }^{4-7}$ are both markers of subsequent asthma risk. How the inter-relationship of these factors relates to persistent respiratory disease is incompletely understood.

The lungs of preterm infants are underdeveloped with immature airways and the association of prematurity with later respiratory disease indicates the developmental origin of asthma. $^{8-10}$ Respiratory infections requiring

\section{ARTICLE SUMMARY}

Strengths and limitations of this study

- The vast majority of infants admitted to hospital with airway infections in their first year after birth in Sweden during the study period will have been identified.

- The use of prospectively recorded national register data allow for longitudinal analysis of asthma risk, with follow-up into early adulthood.

- The infections are incompletely characterised, particularly during earlier years.

- Asthma was identified based on inpatient diagnoses and prescribed medication, but it was not possible to confirm the accuracy of diagnoses.

hospital admission during the first year after birth may signal susceptibility to asthma or may be causally implicated in asthma aetiology; and these explanations are not necessarily mutually exclusive. Respiratory infection epidemics that produce infections among infants are associated with a raised risk of persistent respiratory disease, ${ }^{11}$ consistent with a causal explanation for at least a proportion of the association.

Earlier research has demonstrated that degree of prematurity is relevant to risk of persistent asthma and bronchiolitis in the first year. ${ }^{6}$ This article investigates whether the combination (interaction) of early respiratory infection with prematurity, when the immature lungs may be particularly susceptible to long-term damage, represents a disproportionately raised risk for persistent respiratory disease. Swedish general population registers were used to identify a cohort of children who were admitted to hospital due to respiratory infection in their first year after birth and they were matched with a cohort of children not admitted to hospital for infection in their first year.

\section{METHODS}

All children in Sweden admitted to hospital for severe infections that affect the airways in 
12 months following birth between 1981 and 1995 were identified $(\mathrm{N}=4233)$. They were individually matched with children who were not admitted to hospital for these infections in their first year $(\mathrm{N}=211594)$; matching for gestational age, region of birth and the month and year of their birth. Each exposed child was matched with five unexposed children, selected at random from among those with relevant characteristics. If fewer than five unexposed infants were available for matching with an exposed infant, all suitable children were selected. Follow-up to identify chronic airway disease (asthma) was up to 2010.

\section{Registers}

This study utilised national Swedish register data that can be linked at the individual level using the unique personal identity number issued to all residents. Information on pregnancy and delivery and other characteristics of mother and baby were obtained through the Medical Birth Register, which has recorded almost every delivery in Sweden since 1973. The Patient Register has had complete national coverage of inpatient diagnoses since 1987 and included outpatient diagnoses since 2000. The Prescription Register has provided information on all prescribed medication since 2005.

\section{Measures}

The Patient Register was used to identify respiratory infections in the first year after birth that resulted in hospital admission; these diagnoses are listed in table 1 . This register also identified diagnoses of lung disease through International Classification of Diseases (ICD) codes consistent with asthma in children and young adults. To avoid surveillance bias (incidental reporting of asthma in children admitted or investigated for other diseases) asthma was only defined as the outcome here when it was the sole diagnosis made at the hospital visit. The prescription register-which records all treatments dispensed though pharmacies (including all prescriptions from primary care) was used to identify pharmaceutical treatments for asthma in children and young adults and the selected treatments are presented in table 1 . The Medical Birth Register provided information on gestational age, birth weight, maternal age at delivery, maternal smoking during pregnancy, maternal asthma, sex of the child, parity and a diagnosis of neonatal chronic lung disease (CLD; ICD-8 776.6 and ICD-9 770H): these measures were categorised as presented in table 2 .

\section{Statistical analysis}

Cox regression was used to estimate HRs associated with asthma after 5 years of age (hospital diagnosis or treatment), with follow-up to first asthma event, exit from the study population or end of the study period, whichever came first. The following independent measures were also included in models individually, then mutually adjusted for each other: respiratory infection in the first year after birth, gestational age, sex, maternal age at delivery, parity, maternal smoking, a maternal diagnosis of asthma, CLD and year of delivery (all modelled as series of binary dummy variables in the categories shown in tables 2 and 3). The non-stratified models (table 3) were not adjusted for birth weight, as it was collinear with gestational age while the stratified models (tables 4

Table 1 Respiratory infections and prescribed asthma treatments

\begin{tabular}{ll}
\hline Respiratory infections during the first year of life & \\
Adenovirus infection & Pneumococcal pneumonia \\
Other specified Adenovirus infection & Pneumonia \\
Bordetella Pertussis & Pneumonia due to Streptococcus \\
Bronchitis & Pneumonia due to Haemophilus influenzae \\
Bronchiolitis & Pneumonia due to respiratory syncytial virus \\
Bronchopneumonia organism unspecified & Other unspecified pneumonia \\
Coxsackie virus infection & Bacterial pneumonia unspecified \\
Cytomegalovirus & Other specified viral pneumonia \\
Echo virus infection & Pneumonia in other infectious diseases classified elsewhere \\
Influenza & Rhinovirus infection \\
Influenza with other respiratory manifestations & Other specified viral infections \\
Influenza unspecified & Suspected viral infections \\
Influenza with pleuropneumonia & Unspecified viral infections \\
Prescribed treatments & \\
Beclomethasone & Omalizumab \\
Budesonide & Salbutamol \\
Flutikasone & Salmeterol \\
Formoterol & Sodiumchromoglicate \\
Indakaterol & Terbutaline \\
Ipratroprium & Theophylline \\
Mometasone & Tiotropium bromide \\
Montelucast & \\
\hline
\end{tabular}


Table 2 Characteristics of the cohorts defined by respiratory infection during the first year of life

\begin{tabular}{|c|c|c|c|}
\hline & $\begin{array}{l}\text { Respiratory infection } \\
\text { in first year } \\
n=42334 \\
(16.7 \%)\end{array}$ & $\begin{array}{l}\text { No respiratory infection } \\
\text { in first year } \\
\mathrm{n}=211594 \\
(83.3 \%)\end{array}$ & $\begin{array}{l}\text { Total } \\
n=253928 \\
(100 \%)\end{array}$ \\
\hline Prescribed asthma medication* & 7485 (17.7) & 26591 (12.6) & 34076 (13.4) \\
\hline Hospital asthma diagnosis* & $420(1.0)$ & $761(0.4)$ & $1181(0.5)$ \\
\hline No asthma* & 34749 (82.1) & $184775(87.3)$ & $219524(86.5)$ \\
\hline \multicolumn{4}{|l|}{ Gestational age (weeks) } \\
\hline$\leq 27$ & $252(0.6)$ & $1221(0.6)$ & $1473(0.6)$ \\
\hline $28-31$ & $723(1.7)$ & $3578(1.7)$ & $4301(1.7)$ \\
\hline $32-36$ & $3906(9.2)$ & $19528(9.2)$ & $23434(9.2)$ \\
\hline $37-41$ & 34839 (82.3) & 174194 (82.3) & 209033 (82.3) \\
\hline$>41$ & 2507 (5.9) & $12535(5.9)$ & $15042(5.9)$ \\
\hline Uncertain & $107(0.3)$ & $538(0.3)$ & $645(0.3)$ \\
\hline \multicolumn{4}{|l|}{ Birth weight (g) } \\
\hline$<1000$ & $241(0.6)$ & $1292(0.6)$ & $1533(0.6)$ \\
\hline$>1000-1500$ & $580(1.4)$ & 2714 (1.3) & 3294 (1.3) \\
\hline$>1500-2000$ & $953(2.3)$ & $4300(2.0)$ & $5253(2.1)$ \\
\hline$>2000-2750$ & $4099(9.7)$ & $18815(8.9)$ & $22914(9.0)$ \\
\hline$>2750-3250$ & $9727(23.0)$ & 47617 (22.5) & $57344(22.6)$ \\
\hline$>3250-4000$ & $20178(47.7)$ & $104693(49.5)$ & 124871 (49.2) \\
\hline$>4000$ & 6426 (15.2) & $31524(14.9)$ & 37950 (14.9) \\
\hline Not recorded & $130(0.3)$ & $639(0.3)$ & $769(0.3)$ \\
\hline \multicolumn{4}{|l|}{ Maternal asthma } \\
\hline Current & $721(1.7)$ & $2754(1.3)$ & $3475(1.4)$ \\
\hline Previous & $210(0.5)$ & $749(0.4)$ & $959(0.4)$ \\
\hline None & $41403(97.8)$ & 208091 (98.3) & 249494 (98.3) \\
\hline \multicolumn{4}{|l|}{ Maternal age at delivery } \\
\hline $13-18$ & $755(1.8)$ & $2917(1.4)$ & $3672(1.5)$ \\
\hline $19-25$ & $14230(33.6)$ & $66604(31.5)$ & $80834(31.8)$ \\
\hline $26-30$ & $15312(36.2)$ & 76752 (36.3) & 92064 (36.3) \\
\hline $31-35$ & $8911(21.0)$ & $46336(21.9)$ & $55247(21.8)$ \\
\hline $36-40$ & $2757(6.5)$ & $16673(7.9)$ & $19430(7.7)$ \\
\hline $41-54$ & $369(0.9)$ & 2312 (1.1) & 2681 (1.1) \\
\hline \multicolumn{4}{|l|}{ Maternal smoking } \\
\hline Non-smoker & $23871(56.4)$ & $134802(63.7)$ & $158673(62.5)$ \\
\hline Smoker & $12429(29.4)$ & 46817 (22.1) & 59246 (23.3) \\
\hline Not recorded & 6034 (14.3) & $29975(14.2)$ & 36009 (14.2) \\
\hline \multicolumn{4}{|l|}{ Child's sex } \\
\hline Female & $17619(41.6)$ & 103007 (48.7) & $120626(47.5)$ \\
\hline Male & 24715 (58.4) & 108587 (51.3) & 133302 (52.5) \\
\hline \multicolumn{4}{|l|}{ Parity } \\
\hline 1 & $12714(30.0)$ & 87275 (41.2) & 99989 (39.4) \\
\hline 2 & $17247(40.7)$ & 74534 (35.2) & 91781 (36.1) \\
\hline 3 & 8270 (19.5) & $34880(16.5)$ & $43150(17.0)$ \\
\hline 4 or more & $4103(9.7)$ & $14905(7.0)$ & $19008(7.5)$ \\
\hline \multicolumn{4}{|l|}{ Chronic lung disease } \\
\hline No & 42272 (99.9) & 211416 (99.9) & 253688 (99.9) \\
\hline Yes & $62(0.1)$ & $178(0.1)$ & $240(0.1)$ \\
\hline
\end{tabular}

and 5) and interaction tests were adjusted for a continuous measure of birth weight. Log-minus-log plots were used to assess whether the proportional hazards assumption was violated: the curves comparing the exposed and unexposed cohorts did not converge and proportionality was maintained.

The main analysis concerns the combination of early infection with gestational age and this was investigated in models for the association of first-year infection with asthma after age 5 years, stratified by gestational age, with adjustment for all of the potential confounding factors described above, with the addition of birth weight modelled as a continuous measure. To assess effect modification by gestational age for the association of early infection with asthma, interaction testing using the entire (non-stratified) study population was 
Table 3 Early life characteristics and subsequent asthma risk after age 5 years

\begin{tabular}{|c|c|c|c|c|c|c|}
\hline Characteristic & Asthma n (\%) & No asthma $n(\%)$ & Unadjusted HR (95\% Cl) & p Value & Adjusted* HR $(95 \% \mathrm{Cl})$ & p Value \\
\hline \multicolumn{7}{|c|}{ Respiratory infection in first year } \\
\hline Yes & 7585 (17.9) & 34749 (82.1) & $1.45(1.41$ to 1.49$)$ & $<0.001$ & 1.51 (1.47 to 1.54$)$ & $<0.001$ \\
\hline No & 26819 (12.7) & 184775 (87.3) & Reference & & Reference & \\
\hline \multicolumn{7}{|c|}{ Maternal asthma } \\
\hline Current & $921(26.5)$ & $2554(73.5)$ & 3.86 (3.61 to 4.12$)$ & $<0.001$ & $1.94(1.82$ to 2.08$)$ & $<0.001$ \\
\hline Previous & $222(23.1)$ & 737 (76.9) & 3.05 (2.67 to 3.48$)$ & $<0.001$ & $1.38(1.21$ to 1.58$)$ & $<0.001$ \\
\hline None & 33261 (13.3) & 216233 (86.7) & Reference & & Reference & \\
\hline \multicolumn{7}{|c|}{ Maternal age at delivery (years) } \\
\hline $13-18$ & $517(14.1)$ & 3155 (85.9) & $0.96(0.88$ to 1.05$)$ & 0.372 & $0.98(0.90$ to 1.07$)$ & 0.625 \\
\hline $19-25$ & $11451(14.2)$ & $69383(85.8)$ & $1.02(1.00$ to 1.05$)$ & 0.069 & $1.03(1.00$ to 1.06$)$ & 0.026 \\
\hline 26-30 & 12249 (13.3) & 79815 (86.7) & Reference & & Reference & \\
\hline $31-35$ & $7276(13.2)$ & $47971(86.8)$ & 0.99 (0.96 to 1.02$)$ & 0.490 & $1.02(0.99$ to 1.05$)$ & 0.140 \\
\hline $36-40$ & 2562 (13.2) & $16868(86.8)$ & $1.00(0.96$ to 1.05$)$ & 0.830 & $1.05(1.01$ to 1.10$)$ & 0.029 \\
\hline $41-54$ & $349(13.0)$ & $2332(87.0)$ & $1.00(0.90$ to 1.12$)$ & 0.934 & $1.05(0.94$ to 1.17$)$ & 0.391 \\
\hline \multicolumn{7}{|l|}{ Maternal smoking } \\
\hline Non-smoker & 21701 (13.7) & 136972 (86.3) & Reference & & Reference & \\
\hline Smoker & $8278(14.0)$ & 50968 (86.0) & $0.93(0.91$ to 0.96$)$ & $<0.001$ & $1.01(0.99$ to 1.04$)$ & 0.380 \\
\hline Not recorded & 4425 (12.3) & 31584 (87.7) & $0.59(0.57$ to 0.61$)$ & $<0.001$ & 0.90 (0.87 to 0.93$)$ & $<0.001$ \\
\hline \multicolumn{7}{|l|}{ Child's sex } \\
\hline Female & $18150(15.0)$ & 102476 (85.0) & 1.25 (1.22 to 1.27$)$ & $<0.001$ & $1.27(1.24$ to 1.29$)$ & $<0.001$ \\
\hline Male & 16254 (12.2) & 117048 (87.8) & Reference & & Reference & \\
\hline \multicolumn{7}{|l|}{ Parity } \\
\hline 1 & $14371(14.4)$ & 85618 (85.6) & Reference & & Reference & \\
\hline 2 & 12230 (13.3) & 79551 (86.7) & $0.93(0.90$ to 0.95$)$ & $<0.001$ & 0.90 (0.88 to 0.93$)$ & $<0.001$ \\
\hline 3 & 5437 (12.6) & $37713(87.4)$ & 0.87 (0.84 to 0.89$)$ & $<0.001$ & $0.84(0.82$ to 0.87$)$ & $<0.001$ \\
\hline 4 or more & 2366 (12.4) & 16642 (87.6) & 0.88 (0.84 to 0.92$)$ & $<0.001$ & $0.81(0.78$ to 0.85$)$ & $<0.001$ \\
\hline \multicolumn{7}{|c|}{ Chronic lung disease } \\
\hline No & 34360 (13.5) & $219328(86.5)$ & Reference & & Reference & \\
\hline Yes & $44(18.3)$ & $196(81.7)$ & 1.59 (1.18 to 2.14$)$ & 0.002 & $1.44(1.06$ to 1.96$)$ & 0.019 \\
\hline
\end{tabular}

Table 4 Respiratory infection in the first year of life and subsequent asthma risk after age 5 years, stratified by gestational age

\begin{tabular}{|c|c|c|c|c|c|c|}
\hline $\begin{array}{l}\text { Infection stratified } \\
\text { by gestational age }\end{array}$ & Asthma n (\%) & No asthma n (\%) & HR $(95 \% \mathrm{Cl})$ & p Value & $\mathrm{HR}^{\star}(95 \% \mathrm{Cl})$ & p Value \\
\hline \multicolumn{7}{|l|}{ Weeks 0-27 } \\
\hline Infection & $52(20.6)$ & $200(79.4)$ & 2.03 (1.47 to 2.80$)$ & \multirow[t]{2}{*}{$<0.001$} & 2.22 (1.59 to 3.09$)$ & \multirow[t]{2}{*}{$<0.001$} \\
\hline No infection & 130 (10.6) & $1091(89.4)$ & Reference & & Reference & \\
\hline \multicolumn{7}{|l|}{ Weeks 28-31 } \\
\hline Infection & 132 (18.3) & $591(81.7)$ & $1.47(1.21$ to 1.78$)$ & \multirow[t]{2}{*}{$<0.001$} & 1.57 (1.29 to 1.92$)$ & \multirow[t]{2}{*}{$<0.001$} \\
\hline No infection & $458(12.8)$ & 3130 (87.2) & Reference & & Reference & \\
\hline \multicolumn{7}{|l|}{ Weeks 32-36 } \\
\hline Infection & 738 (18.9) & 3168 (81.1) & $1.47(1.35$ to 1.59$)$ & \multirow[t]{2}{*}{$<0.001$} & 1.54 (1.42 to 1.68$)$ & \multirow[t]{2}{*}{$<0.001$} \\
\hline No infection & 2588 (13.3) & 16940 (86.7) & Reference & & Reference & \\
\hline \multicolumn{7}{|l|}{ Weeks 37-41 } \\
\hline Infection & $6194(17.8)$ & 28645 (82.2) & $1.44(1.40$ to 1.48$)$ & \multirow[t]{2}{*}{$<0.001$} & 1.49 (1.45 to 1.53$)$ & \multirow[t]{2}{*}{$<0.001$} \\
\hline No infection & 22075 (12.7) & 152119 (87.3) & Reference & & Reference & \\
\hline \multicolumn{7}{|l|}{ Weeks $>41$} \\
\hline Infection & $446(17.8)$ & 2061 (82.2) & $1.51(1.36$ to 1.68$)$ & \multirow[t]{2}{*}{$<0.001$} & $1.57(1.41$ to 1.75$)$ & \multirow[t]{2}{*}{$<0.001$} \\
\hline No infection & $1512(12.1)$ & 11023 (87.9) & Reference & & Reference & \\
\hline \multicolumn{7}{|l|}{ Weeks uncertain } \\
\hline Infection & $23(21.5)$ & $84(78.5)$ & $2.10(1.29$ to 3.42$)$ & \multirow[t]{2}{*}{0.003} & 2.21 (1.34 to 3.65$)$ & \multirow[t]{2}{*}{0.002} \\
\hline No infection & $56(10.4)$ & 482 (89.6) & Reference & & Reference & \\
\hline
\end{tabular}

${ }^{*}$ Adjusted for child's sex, maternal asthma, maternal age at delivery, year of birth, birth weight, maternal smoking, infection during first year of life, parity and chronic lung disease. 
Table 5 Respiratory infection in the first year of life and subsequent asthma risk after age 10 years and after age 16 years, stratified by gestational age

\begin{tabular}{|c|c|c|c|c|c|c|}
\hline & Asthma n (\%) & No asthma $n(\%)$ & HR (95\% Cl) & p Value & $\mathrm{HR}^{\star}(95 \% \mathrm{Cl})$ & p Value \\
\hline \multirow{2}{*}{\multicolumn{7}{|c|}{$\begin{array}{l}\text { Asthma } \geq \text { age } 10 \text { years } \\
\text { Gestational age (weeks) } \\
\leq 27\end{array}$}} \\
\hline & & & & & & \\
\hline Infection & $45(17.9)$ & 207 (82.1) & 1.83 (1.30 to 2.57 ) & 0.001 & 1.99 (1.40 to 2.82$)$ & $<0.001$ \\
\hline No infection & 123 (10.1) & 1098 (89.9) & Reference & & Reference & \\
\hline \multicolumn{7}{|l|}{ 28-31 } \\
\hline Infection & $116(16.0)$ & 607 (84.0) & $1.43(1.17$ to 1.76$)$ & 0.001 & $1.52(1.24$ to 1.87$)$ & $<0.001$ \\
\hline No infection & $411(11.5)$ & 3167 (88.5) & Reference & & Reference & \\
\hline \multicolumn{7}{|l|}{ 32-36 } \\
\hline Infection & 635 (16.3) & 3271 (83.7) & 1.39 (1.27 to 1.52$)$ & $<0.001$ & $1.46(1.33$ to 1.59$)$ & $<0.001$ \\
\hline No infection & $2328(11.9)$ & $17200(88.1)$ & Reference & & Reference & \\
\hline \multicolumn{7}{|l|}{ 37-41 } \\
\hline Infection & $5541(15.9)$ & 29298 (84.1) & $1.44(1.40$ to 1.48$)$ & $<0.001$ & $1.49(1.45$ to 1.54$)$ & $<0.001$ \\
\hline No infection & 19637 (11.3) & 154557 (88.7) & Reference & & Reference & \\
\hline \multicolumn{7}{|l|}{$>41$} \\
\hline Infection & 397 (15.8) & 2110 (84.2) & 1.51 (1.35 to 1.69$)$ & $<0.001$ & 1.57 (1.41 to 1.76$)$ & $<0.001$ \\
\hline No infection & $1340(10.7)$ & 11195 (89.3) & Reference & & Reference & \\
\hline \multicolumn{7}{|l|}{ Uncertain } \\
\hline Infection & $19(17.8)$ & $88(82.2)$ & $1.93(1.14$ to 3.28$)$ & 0.015 & 2.05 (1.19 to 3.55$)$ & 0.010 \\
\hline No infection & $50(9.3)$ & $488(90.7)$ & Reference & & Reference & \\
\hline \multicolumn{7}{|c|}{ Asthma $\geq$ age 16 years } \\
\hline \multicolumn{7}{|l|}{$\leq 27$} \\
\hline Infection & $22(8.8)$ & 227 (91.2) & 1.56 (0.96 to 2.52$)$ & 0.068 & 1.65 (1.01 to 2.71$)$ & 0.047 \\
\hline No infection & $69(5.7)$ & $1132(94.3)$ & Reference & & Reference & \\
\hline \multicolumn{7}{|l|}{ 28-31 } \\
\hline Infection & $65(9.2)$ & $638(90.8)$ & $1.41(1.07$ to 1.86$)$ & 0.014 & $1.45(1.10$ to 1.91$)$ & 0.009 \\
\hline No infection & $233(6.7)$ & 3249 (93.3) & Reference & & Reference & \\
\hline \multicolumn{7}{|l|}{ 32-36 } \\
\hline Infection & $396(10.5)$ & 3362 (89.5) & $1.43(1.28$ to 1.60$)$ & $<0.001$ & 1.49 (1.34 to 1.68$)$ & $<0.001$ \\
\hline No infection & $1410(7.5)$ & $17379(92.5)$ & Reference & & Reference & \\
\hline \multicolumn{7}{|l|}{$37-41$} \\
\hline Infection & $3227(9.7)$ & $30040(90.3)$ & $1.37(1.32$ to 1.42$)$ & $<0.001$ & $1.42(1.37$ to 1.48$)$ & $<0.001$ \\
\hline No infection & $11987(7.2)$ & 154347 (92.8) & Reference & & Reference & \\
\hline \multicolumn{7}{|l|}{$>41$} \\
\hline Infection & $248(10.3)$ & $2161(89.7)$ & 1.58 (1.37 to 1.82$)$ & $<0.001$ & 1.64 (1.42 to 1.90$)$ & $<0.001$ \\
\hline No infection & $801(6.7)$ & 11244 (93.3) & Reference & & Reference & \\
\hline \multicolumn{7}{|l|}{ Uncertain } \\
\hline Infection & $16(15.2)$ & $89(84.8)$ & 2.48 (1.37 to 4.51$)$ & 0.003 & $2.72(1.47$ to 5.04$)$ & 0.002 \\
\hline No infection & $33(6.2)$ & $496(93.8)$ & Reference & & Reference & \\
\hline
\end{tabular}

undertaken. The interaction term for gestational age by infection (categorical) was adjusted for the main effects (gestational age and infection), as well as for all of the previously described potential confounding factors.

To assess whether the combination of prematurity with first-year infection is a risk for asthma that persists beyond early childhood, the above analysis stratified for gestational age was repeated, but with truncated follow-up to identify asthma after age 10 years and after age 16 years.

SPSS software was used and statistical significance was defined as CIs that do not include 1.00 and $p$ values below 0.05 .

\section{RESULTS}

As the two cohorts were matched, the distributions for gestational age and year of birth are almost identical (table 2). This matching is also reflected in the very similar distributions for birth weight. Children admitted to hospital with infections were more often male and their mothers were more likely to be younger, smokers, to have a diagnosis of asthma, and to have had a greater number of previous pregnancies. CLD was also more common in the infection cohort, particularly among the extremely preterm infants $(12.3 \%$ compared with $7.9 \%$ among the extremely preterm).

Respiratory infection during the first year is statistically significantly associated with a raised risk of asthma after 
age 5 years, before as well as after adjustment for potential confounding factors (table 3). Female sex, neonatal lung disease, maternal asthma and fewer previous pregnancies are associated with statistically significantly raised asthma risk in the adjusted model. Gestational age was a matching characteristic, hence associations with this measure are not presented.

Table 4 shows the association of hospital admission for infection in the first year with asthma after age 5 years, stratified by gestational age. Infection is associated with asthma across all of the gestational age groups after adjustment for potential confounding factors. The highest magnitude association is among the most preterm infants. A notably raised risk was also observed among those with uncertain gestational age. Interaction testing among the entire study population confirms statistically significant effect modification by the most premature gestational age group, at less than 28 weeks compared with the infants who were born at term. The interaction results were not statistically significant for the other gestational age groups, including where it was unspecified. After adjustment for the main effects the HR for interaction (and 95\% CI) is 1.41 (1.02 to 1.95; p for interaction $=0.034$ ) and with additional adjustment for the potential confounding factors it is 1.40 (1.01 to 1.93; $p$ for interaction $=0.042$ ).

Early infection is associated with asthma after age 10 and after age 16 years for all gestational age groups, but although still statistically significant, the notably increased magnitude for the most premature is somewhat reduced after age 16 years (table 5 ).

The analysis was repeated excluding those with missing maternal smoking information and the results were not notably altered (data not shown).

\section{DISCUSSION}

In this register-based cohort study, hospital admission for respiratory infection in the 12 months following birth was associated with an increased risk of asthma after age 5 years, particularly among those born extremely prematurely.

Another study using Swedish register data found that early infection and prematurity were independently associated with later increased corticosteroid use. ${ }^{6}$ While the results between the earlier study and ours are similar for associations with infection, the cohorts in our study were matched for gestational age, which was considered as a potential modifying factor for the effect of early infections. Here, asthma after age 5 years was identified through prescribed corticosteroids and other asthma medication, as well as inpatient or outpatient hospital diagnoses. We used several strategies to ensure that the associations are with asthma rather than other comorbidity associated with prematurity and early infection. Only diagnoses of asthma made after age 5 years were included, as these are more likely to represent persistent asthma. We limited diagnoses to instances where asthma was the sole diagnosis recorded by the outpatient or inpatient discharge summary to minimise surveillance bias, where admission for another condition results in an incidental diagnosis of asthma: this can produce a conservative estimate of association. While it can be difficult to differentiate between the effects of infection and susceptibility to infection, we attempted to tackle this through adjustment for a variety of potential confounding factors, including birth weight within gestational age categories to provide fine-grain control for fetal development. The extremely preterm infants more often had CLD, possibly signalling greater susceptibly to both early infection and also asthma: we therefore adjusted for neonatal CLD.

This study has some potential limitations. Identification of asthma through registers does not provide information about disease phenotype, including whether allergic sensitisation is implicated and confirmation of individual diagnoses is not possible. The infections defining the exposed cohort are not always well characterised (particularly from the earlier periods), but all will affect the lungs and were sufficiently serious to result in hospital admission. Prior to 1990, respiratory syncytial virus (RSV) was often diagnosed as an unspecified viral infection; we therefore included some non-specific infections. Earlier studies found that RSV was responsible for the majority of bronchiolitis diagnoses during the first year after birth, ${ }^{12}{ }^{13}$ while rhinovirus was associated with $18 \%$ of bronchiolitis diagnoses, although hospital admission was less common. ${ }^{14}$ It is possible that use of more specific diagnoses, not available through the patient register, would result in higher magnitude associations. We were unable to examine delivery mode as a potential confounding factor as this was not available in our data set: caesarean section has been linked with an increased asthma risk in term infants. ${ }^{15}$ Number of older siblings is an important indicator of asthma risk. While this was not measured directly, we adjusted for parity as a reliable indicator of number of older siblings. Also, it has been hypothesised that previous pregnanciesdirectly measured by parity-may influence immunemediated disease risk through changes in the mother's immune profile. ${ }^{16}$ The measure of maternal smoking was incomplete as it was not always included in the Medical Birth Register. The proportions without smoking data were almost identical in both the exposed and unexposed cohorts. When the analysis was restricted to mothers with complete smoking data, the results were not materially altered. Our study will have underestimated the total number of asthma diagnoses, as we did not have data from primary care and because we excluded asthma with comorbid diagnoses to avoid confounding by comorbidity. The use of prescribed medication will have improved our ability to identify chronic asthma as this will identify those diagnosed and treated in primary care. The two strategies to identify asthma were combined to maximise reliable asthma identification and statistical power. Unavoidably, gestational age was unavailable for some infants: the higher magnitude asthma risk associated with infections in this group may be due to a proportion who were also very 
premature, and possibly other risks. As interaction testing by gestational age was undertaken, adjustment rather than internal stratification for this factor was performed. Despite this, use of a matching characteristic may still have resulted in underestimation of interaction effects between infection and gestational age.

RSV as well as rhinovirus infections in infancy have been linked with subsequent childhood wheezing, ${ }^{1}{ }^{3}$ but the association of early life infections with allergy and possible asthma risk has a complicated pattern. While some markers of infection, such as positive serology for Epstein-Barr virus (EBV) and cytomegalovirus (CMV) are associated with a reduced risk of allergic sensitisation, ${ }^{17}$ there is evidence that early infection with RSV may increase the risk of allergic asthma through its influence on regulatory $\mathrm{T}$ cell function. ${ }^{18}$ However, pre-existing atopy-or associated characteristics-may also influence subsequent infection risk, as rhinovirus bronchiolitis has been found to occur more frequently in infants who had prior allergic sensitisation. ${ }^{19}$ Whether or not allergy is implicated, respiratory infections in infancy, RSV as well as non-RSV infections, are thought to contribute to airway impairment. ${ }^{3}$ 20-23 The possible non-mutually exclusive mechanisms include through structural damage, ${ }^{24}$ modification of the mucosal immunology of the lungs ${ }^{25}$ or through epigenetic changes. ${ }^{26}$ Treatment of infections by antibiotics has been suggested as a risk for asthma, but the evidence is weak; and reviews suggest that the association is due to confounding by indication.

Lung development continues throughout fetal life and babies born prematurely have developmental deficits of the airways ${ }^{27-30}$ that may result in chronic asthma, ${ }^{8}$ which can diminish with increasing age as lung function improves. ${ }^{31} 32$ Atopic sensitisation-and thus allergic asthma that may be more persistent in adulthood-is less common in those born preterm compared with term deliveries. ${ }^{33}$ Thus, the combination of early infection and prematurity may conspire to increase allergic as well as non-allergic risks for asthma, helping to explain the multiplicative effect of this combination of exposures for the risk of subsequent asthma. The notably higher risk of asthma associated with this exposure combination continues throughout childhood, but appears to be less profound after age 16 years, possibly reflecting age-associated changes.

This study provides evidence that respiratory infections resulting in hospital admission during the first year after birth are a risk for subsequent asthma after age 5 years. The increase in childhood asthma risk is particularly high among extremely preterm infants.

\footnotetext{
Author affiliations

${ }^{1}$ Clinical Epidemiology and Biostatistics, Örebro University Hospital \& Örebro University, Örebro, Sweden

${ }^{2}$ The Clinical Epidemiology Unit, Karolinska Institutet, Stockholm, Sweden ${ }^{3}$ Department of Epidemiology and Public Health, University College London, UK

${ }^{4}$ The Centre for Pharmacoepidemiology, Karolinska Institutet, Stockholm, Sweden
}

${ }^{5}$ Department of Woman and Child Health, Karolinska Institutet, Stockholm, Sweden

${ }^{6}$ Division of Neonatology, Karolinska Hospital, Stockholm, Sweden

Contributors SM and CP-K conceived the study and prepared the first draft of the manuscript and with SB they developed the methods. SB and PK were responsible for obtaining and preparing the data. $\mathrm{OB}$ and $\mathrm{OH}$ conducted the statistical analysis and produced the tables. All authors were involved in critical editing of the manuscript.

Funding The study was supported by the Abbvie Research Fund and Örebro University strategic funding.

\section{Competing interests None.}

Ethics approval Karolinska Regional Ethics Committee, Stockholm.

Data sharing statement We do not have ethical permission to share the data, however they are register data and available to other academic researchers.

Open Access This is an Open Access article distributed in accordance with the Creative Commons Attribution Non Commercial (CC BY-NC 3.0) license, which permits others to distribute, remix, adapt, build upon this work noncommercially, and license their derivative works on different terms, provided the original work is properly cited and the use is non-commercial. See: http:// creativecommons.org/licenses/by-nc/3.0/

\section{REFERENCES}

1. Sigurs N, Aljassim F, Kjellman B, et al. Asthma and allergy patterns over 18 years after severe RSV bronchiolitis in the first year of life. Thorax 2010;65:1045-52.

2. Hyvarinen MK, Kotaniemi-Syrjanen A, Reijonen TM, et al. Lung function and bronchial hyper-responsiveness 11 years after hospitalization for bronchiolitis. Acta Paediatr 2007;96:1464-9.

3. Jackson DJ, Gangnon RE, Evans MD, et al. Wheezing rhinovirus illnesses in early life predict asthma development in high-risk children. Am J Respir Crit Care Med 2008;178:667-72.

4. Kallen B, Finnstrom O, Nygren KG, et al. Association between preterm birth and intrauterine growth retardation and child asthma. Eur Respir J 2013;41:671-6.

5. Vrijlandt EJ, Kerstjens JM, Duiverman EJ, et al. Moderately preterm children have more respiratory problems during their first 5 years of life than children born full term. Am J Respir Crit Care Med 2013;187:1234-40.

6. Vogt $\mathrm{H}$, Lindstrom K, Braback $\mathrm{L}$, et al. Preterm birth and inhaled corticosteroid use in 6- to 19-year-olds: a Swedish national cohort study. Pediatrics 2011;127:1052-9.

7. Doyle LW. Respiratory function at age 8-9 years in extremely low birthweight/very preterm children born in Victoria in 1991-1992. Pediatr Pulmonol 2006;41:570-6.

8. Fawke J, Lum S, Kirkby J, et al. Lung function and respiratory symptoms at 11 years in children born extremely preterm: the EPICure study. Am J Respir Crit Care Med 2010;182:237-45.

9. Jaakkola JJ, Ahmed $\mathrm{P}$, leromnimon A, et al. Preterm delivery and asthma: a systematic review and meta-analysis. J Allergy Clin Immunol 2006;118:823-30.

10. Greenough A. Long-term pulmonary outcome in the preterm infant Neonatology 2008;93:324-7.

11. Wu P, Hartert TV. Evidence for a causal relationship between respiratory syncytial virus infection and asthma. Expert Rev Anti Infect Ther 2011;9:731-45.

12. Broughton S, Roberts A, Fox G, et al. Prospective study of healthcare utilisation and respiratory morbidity due to RSV infection in prematurely born infants. Thorax 2005;60:1039-44.

13. Wickman M, Farahmand BY, Persson PG, et al. Hospitalization for lower respiratory disease during 20 yrs among under 5 yr old children in Stockholm County: a population based survey. Eur Respir J 1998;11:366-70.

14. Miller EK, Williams JV, Gebretsadik T, et al. Host and viral factors associated with severity of human rhinovirus-associated infant respiratory tract illness. J Allergy Clin Immunol 2011;127:883-91.

15. Almqvist $C$, Cnattingius $S$, Lichtenstein $P$, et al. The impact of birth mode of delivery on childhood asthma and allergic diseases-a sibling study. Clin Exp Allergy 2012;42:1369-76.

16. Amoudruz $P$, Holmlund $U$, Schollin J, et al. Maternal country of birth and previous pregnancies are associated with breast milk characteristics. Pediatr Allergy Immunol 2009;20:19-29. 
17. Nilsson $\mathrm{C}$, Linde A, Montgomery SM, et al. Does early EBV infection protect against IgE sensitization? J Allergy Clin Immunol 2005;116:438-44.

18. Krishnamoorthy $\mathrm{N}$, Khare A, Oriss TB, et al. Early infection with respiratory syncytial virus impairs regulatory $T$ cell function and increases susceptibility to allergic asthma. Nat Med 2012;18:1525-30.

19. Jackson DJ, Evans MD, Gangnon RE, et al. Evidence for a causal relationship between allergic sensitization and rhinovirus wheezing in early life. Am J Respir Crit Care Med 2012;185:281-5.

20. Fjaerli HO, Farstad T, Rod G, et al. Acute bronchiolitis in infancy as risk factor for wheezing and reduced pulmonary function by seven years in Akershus County, Norway. BMC Pediatr 2005;5:31.

21. Romero JR, Stewart DL, Buysman EK, et al. Serious early childhood wheezing after respiratory syncytial virus lower respiratory tract illness in preterm infants. Clin Ther 2010;32:2422-32.

22. Koponen $\mathrm{P}$, Helminen $\mathrm{M}$, Paassilta $\mathrm{M}$, et al. Preschool asthma after bronchiolitis in infancy. Eur Respir J 2012;39:76-80.

23. Mikalsen IB, Halvorsen T, Oymar K. The outcome after severe bronchiolitis is related to gender and virus. Pediatr Allergy Immunol 2012;23:391-8.

24. Benjamin JT, Carver BJ, Plosa EJ, et al. NF-kappaB activation limits airway branching through inhibition of Sp1-mediated fibroblast growth factor-10 expression. J Immunol 2010;185:4896-903.
25. Han J, Takeda K, Gelfand EW. The role of RSV infection in asthma initiation and progression: findings in a mouse model. Pulm Med 2011;2011:748038.

26. Joss-Moore LA, Lane RH. Epigenetics and the developmental origins of disease: the key to unlocking the door of personalized medicine. Epigenomics 2012;4:471-3.

27. Hjalmarson O, Sandberg K. Abnormal lung function in healthy preterm infants. Am J Respir Crit Care Med 2002;165:83-7.

28. Friedrich $\mathrm{L}$, Pitrez PM, Stein RT, et al. Growth rate of lung function in healthy preterm infants. Am J Respir Crit Care Med 2007;176:1269-73.

29. Boyle EM, Poulsen G, Field DJ, et al. Effects of gestational age at birth on health outcomes at 3 and 5 years of age: population based cohort study. BMJ 2012;344:e896.

30. Kotecha SJ, Watkins WJ, Paranjothy S, et al. Effect of late preterm birth on longitudinal lung spirometry in school age children and adolescents. Thorax 2012;67:54-61.

31. Narang I, Rosenthal M, Cremonesini D, et al. Longitudinal evaluation of airway function 21 years after preterm birth. Am J Respir Crit Care Med 2008;178:74-80.

32. Crump C, Winkleby MA, Sundquist J, et al. Risk of asthma in young adults who were born preterm: a Swedish national cohort study. Pediatrics 2011;127:e913-20.

33. Siltanen M, Wehkalampi K, Hovi P, et al. Preterm birth reduces the incidence of atopy in adulthood. J Allergy Clin Immunol 2011;127:935-42. 